\title{
INVESTIGASI MODEL MENTAL KONDUKSI KALOR SISWA SMA
}

\author{
Elsa Karolina ${ }^{1}$, Ika Mustika Sari' ${ }^{1}$ dan Irma Rahma Suwarma ${ }^{1}$ \\ ${ }_{1}^{1}$ Pendidikan Fisika, FPMIPA, Universitas Pendidikan Indonesia, Bandung, Indonesia \\ E-mail: karolinaelsa98@student.upi.edu
}

\begin{abstract}
ABSTRAK
Penelitian ini bertujuan untuk menginvestigasi profil model mental konduksi kalor siswa SMA yang belum belajar kalor dan siswa SMA yang sudah belajar kalor. Metode yang digunakan pada penelitian ini adalah deskriptif kualitatif. Partisipan yang terlibat pada penelitian ini adalah siswa belum belajar materi kalor (Kelas X) 15 orang dan siswa sudah belajar materi kalor (Kelas XI) 15 orang dari salah satu SMA Negeri di Kabupaten Bandung. Instrumen yang digunakan berupa protokol wawancara dari Chiou (2010) yang terdiri dari tiga tahapan. Hasil penelitian ini menunjukkan bahwa pada kelompok siswa yang belum belajar kalor tidak ditemukan siswa yang memiliki model mental ilmiah. Kemudian untuk kelompok siswa yang sudah belajar kalor ditemukan dua siswa memiliki model mental yang ilmiah, 12 siswa memiliki model mental tidak ilmiah dan satu siswa tidak memiliki model mental konduksi kalor karena tidak mampu menjelaskan konsep kalor. Hasil tersebut menunjukkan tidak terdapat perbedaan yang signifikan model mental siswa yang belum belajar kalor dengan siswa yang sudah belajar kalor. Oleh karena itu, diperlukan pengembangan model pembelajaran yang dapat memfasilitasi pembentukan model mental ilmiah.
\end{abstract}

Kata kunci: model mental, konsepsi konduksi kalor, analogi proses

\begin{abstract}
This descriptive qualitative research aims to investigate the mental model profile of heat conduction towards high school students who have and have not learned regarding heat. The participants involved in this study are 15 students who have not studied heat material $\left(10^{\text {th }}\right.$ Grade) and 15 students who have studied it (1 $1^{\text {th }}$ Grade) from one of the public high schools in Bandung Regency. The instrument used was an interview protocol from Chiou (2010) which consisted of three stages. The research findings indicate that in the group of students who had not taken the heat lesson, none of them had the scientific mental models. Moreover, it was found in the group of students who already learned about heat that two students had the scientific mental model, 12 students had the unscientific mental model and one student did not possess the heat conduction mental model by reason of his incompetency in explaining the heat concept. These results indicate that there is no significant difference in the mental models between students who have learned and have not learned heat. Thus, it is necessary to develop a learning model that can facilitate the establishment of scientific mental models.
\end{abstract}

Keywors: mental models, scientific heat conduction, process analogy

DOI: http://dx.doi.org/10.15575/jotalp.v6i1.10987

Received: 20 Januari 2021 ; Accepted: 7 Februari 2021 ; Published: 28 Februari 2021 


\section{PENDAHULUAN}

Pendidikan Nasional berfungsi mengembangkan kemampuan dan membentuk watak serta peradaban bangsa yang bermanfaat dalam rangka mencerdaskan kehidupan bangsa. Hal ini diatur dalam Undang-Undang No. 20 tahun 2003, yang di dalamnya dijelaskan bahwa pendidikan nasional memiliki tujuan untuk mengembangkan potensi peserta didik agar menjadi manusia yang beriman dan bertakwa kepada Tuhan Yang Maha Esa, berakhlak mulia, sehat, berilmu, cakap, kreatif, mandiri, dan menjadi warga negara yang demokratis serta bertanggung jawab. Salah satu tujuan pembelajaran fisika yang tertuang dalam kerangka kurikulum 2013 ialah menguasai konsep dan prinsip serta mempunyai keterampilan mengembangkan pengetahuan dan sikap percaya diri sebagai bekal untuk melanjutkan pendidikan pada jenjang yang lebih tinggi serta mengembangkan ilmu pengetahuan dan teknologi (Kemendikbud, 2014).

Berdasarkan tujuan tersebut, pembelajaran fisika di sekolah harus mampu membangun konsep yang utuh, keselarasan antara fakta-fakta dan konsep dasar harus dimiliki siswa. Sekolah harus mampu mendorong lima hal inti dalam pembentukan organisasi pembelajar yaitu: (1) Pemikiran Sistem (System Thinking), (2) Keahlian Pribadi (Personal Mastery), (3) Model Mental (Mental Model), (4) Visi Bersama (Building Shared), (5) Pembelajaran Tim (Tim Learning). Dari kelima komponen tersebut, model mental menjadi salah satu hal yang belum diterapkan dalam pembelajaran (Senge 2004).

Model mental adalah representasi dinamis dan generative yang dapat dimanipulasi secara mental untuk memberikan penjelasan kausal fenomena fisik dan membuat prediksi tentang keadaan di dunia fisik (Supriyatman et al. 2018). Untuk menjelaskan sebuah fenomena, model mental bertindak sebagai peran "pengganti" untuk menggambarkan konsep tersebut. Inilah yang kemudian dinamakan dengan model mental (Jansoon, Coll, dan Somsook 2009)
Dalam model mental tidak ada kata "benar" atau "salah". Perbedaan model mental tiap individu menunjukkan bentuk konsistensi internal dalam memahami konsep-konsep fisika yang dapat (Rahayu dan Purwanto 2013). Penggalian model mental pada materi-materi khusus yang berkaitan dengan kehidupan sehari-hari berperan penting karena ketika suatu model mental dapat diterima secara ilmiah maka seseorang itu mampu memprediksi suatu fenomena fisis.

Materi-materi fisika yang erat kaitannya dengan kehidupan sehari-hari yaitu seperti suhu dan kalor, pemanasan global, listrik dll. Chiou \& Anderson (2010) menyatakan bahwa sebagian mahasiswa yang menganggap aliran kalor konduksi itu merupakan aliran tak bermassa dan tak terlihat, bukan dianggap sebagai interaksi antarpartikel yang saling bergetar. Hal ini yang kurang digali dari penelitian-penelitian pendidikan fisika. Penggalian model mental pada materi-materi khusus memberikan masukan yang sangat baik bagi pembelajaran fisika terutama dalam mengetahui penyebab-penyebab terjadinya miskonsepsi dalam suatu konsep fisika. Konsep dasar yang dimiliki siswa tersebut dapat sesuai dengan konsep ilmiah tetapi dapat juga tidak sesuai dengan konsep ilmiah (Wenning 2008). Keadaan tersebut dapat menimbulkan miskonsepsi.

Tingginya miskonsepsi yang terjadi dapat diketahui penyebab terjadinya melalui gambaran model mental siswa. Sesuai dengan penelitian Fauzi (2017) diperoleh hasil terdapat hubungan model mental dengan miskonsepsi, dengan 75\% siswa termasuk kedalam kategori miskonsepsi yang dikarenakan sekitar $65 \%$ siswa memiliki model mental yang tidak diterima secara ilmiah. Penelitian yang sama juga dilakukan oleh Amalia, Sari, \& Sinaga (2016) yaitu mengenai hubungan tingkat konsepsi dengan model mental siswa, meskipun hasil yang diperoleh tidak spesifik namun tidak terdapat siswa yang memiliki konsep ilmiah dan model mental ilmiah. Hamzah, 
Liliawati, \& Samsudin (2019) melakukan penelitian di 61 SMA Provinsi Jawa Barat, dilaporkan bahwa peserta didik yang memiliki pemahaman konsep saintifik masih rendah yaitu $37 \%$, lemah dalam pengetahuan $17 \%$, dan kesalahan pemahaman suatu konsep 7\%. Norman (1983) menjelaskan bahwa terdapat hubungan linear antara profil pemahaman konseptual dan model mental. Sementara kita ketahui bahwa analisis pemahaman konsep dalam pembelajaran fisika merupakan salah satu upaya dalam mencapai tujuan pembelajaran (Bohori dan Liliawati 2019)

Model mental siswa bersifat dinamis, artinya dapat berubah dengan adanya informasi yang diperoleh (Bonello 2008). Faktor-faktor yang mempengaruhi model mental siswa yang beragam di kelompokkan menjadi lima, yaitu (a) penjelasan guru, (b) bahasa dan kata-kata (c) pengalaman hidup sehari-hari (d) lingkungan sosial (e) hubungan sebab akibat dan intuisi (Lin dan Chiu 2007). Menjadi keunikan sekaligus tantangan dalam penelitian model mental, karena model mental bersifat tidak tetap dan berbedabeda setiap individu (Lin dan Chiu 2007). Belajar membuat seseorang mengetahui hal yang baru, mengerti dengan hal yang belum dipahaminya dan dengan belajar mampu mengubah perilaku seseorang karena pengaruh hal lain yang ia pelajari (Shalihah, Mulhayayiah, dan Alatas 2019). Melalui pembelajaran sains, siswa diharapkan untuk mengamati fenomena yang mereka temukan dalam kehidupan sehari-hari dan menganalisis pola sehinga pada akhir proses mereka mampu prediksi perilaku pada fenomena lain (Sari et al. 2019)

Model mental yang dimiliki siswa sangat penting bagi guru, baik untuk menentukan strategi pembelajaran yang cocok dalam pembelajaran kedepannya, bahan ajar, ataupun media yang disusun agar pemahaman siswa mengenai suatu konsep menjadi satu kesatuan utuh(Rahayu dan Purwanto 2013). Model mental yang ilmiah tidak akan dimiliki siswa ketika pembelajarannya hanya dengan metode ceramah dan mengedepankan hafalan. Pada penelitian Sari (2019) ditemukan 61,36\% siswa menyebutkan bahwa guru menjelaskan suatu materi hanya dengan metode ceramah, padahal 81,52\% menyatakan lebih mengerti suatu materi pelajaran jika dijelaskan dengan gambar dibandingkan dengan ceramah saja. Penggalian model mental bertujuan untuk meningkatkan kualitas belajar berdasarkan penggambaran konsepsi siswa dan representasi internal (Sari dan Saepuzzaman 2016). Penelitian ini bertujuan untuk mengivestigasi profil model mental yang miliki siswa SMA Negeri di Kabupaten Bandung kelas X yaitu siswa yang belum belajar kalor dan kelas XI yaitu siswa yang sudah belajar kalor dalam menjelaskan konduksi kalor. Model mental siswa SMA dalam menjelaskan konduksi kalor mengacu pada penelitian Chiou \& Anderson (2010).

\section{METODE PENELITIAN}

Metode penelitian ini merupakan penelitian deskriptif kualitatif dimana data diperoleh berdarkan wawancara. Penelitian ini dilakukan di salah satu SMA Negeri di Kabupaten Bandung. Subjek penelitian ini adalah siswa kelas X IPA 5 yaitu siswa yang belum belajar materi kalor sebanyak 15 orang dan siswa kelas XI IPA 2 yaitu siswa yang sudah belajar materi kalor sebanya 15 orang. Wawancara dilakukan kepada total 30 siswa melalui video call whatsapp dan membuat membuat rekaman suara wawancara. Penelitian ini dilakukan selama 3 minggu di bulan Juli 2020 .

Instrumen utama penelitian ini adalah protokol wawancara dari (Chiou dan Anderson 2010). Wawancara yang dilakukan merupakan wawancara semi terstruktur untuk menggali model mental konduksi kalor yang dimiliki siswa. Kemudian analisis data dilakukan dengan mereduksi data, menyajikan data dalam bentuk tabel, mengecek reliabilitas data dengan menentukan nilai kappa menggunakan SPSS seperti yang ditunjukkan pada tabel 1, kemudian menarik kesimpulan. 
Tabel 1. Tabel Kategori tingkat reliabilitas

\begin{tabular}{cc}
\hline Nilai & Kategori \\
\hline Kappa $<0,4$ & Buruk \\
\hline Kappa 0,4-0,6 & Cukup \\
\hline Kappa 0,6-0,75 & Baik \\
\hline Kappa $>0,75$ & Sangat Baik \\
\hline
\end{tabular}

(Widhiarso 2005)

\section{HASIL DAN PEMBAHASAN}

Model mental siswa yang ditemukan merupakan hubungan antara konsep konduksi kalor dengan analogi proses konduksi kalor. Model mental siswa didasarkan pada kekonsistenan pola jawaban siswa terhadap sesuatu (Bonello 2008).

\section{Konsepsi Konduksi Kalor}

Kategori konsepsi kalor diperoleh melalui wawancara pada tahap pertama untuk mengetahui pemahaman siswa. Konsepsi konduksi kalor yang dimiliki siswa disajikan pada tabel 2.

Tigabelas kategori konsepsi konduksi kalor ditemukan dalam penelitian ini. Tigabelas konsepsi ini merupakan pengembangan dari studi sebelumnya oleh Chiou \& Anderson (2010). Kelompok responden pertama yaitu siswa belum belajar kalor dominan berada pada kategori material motion yaitu sebanyak empat siswa. Pada kategori energy dan material motion-cycle masing-masing sebanyak tiga siswa. Kategori energy merupakan konsepsi kalor yang paling baik pada kelompok siswa belum belajar kalor. Pada kelompok responden ini terdapat kategori konsep yang dipertukarkan yaitu medium samplebased convection dan radiation, masing-masing kategori tersebut terdapat satu siswa. Penyebab terjadinya konsep yang dipertukarkan ini karena siswa cenderung memahami fisika dengan hafalan. Menurut Mayub (2005) pembelajaran yang diterima siswa hanyalah penekanan tingkat hafalan dari berbagai topik atau pokok bahasan, tetapi tidak diikuti oleh pemahaman atau pengertian yang mendalam, yang bisa diterapkan oleh siswa ketika berhadapan dengan situasi batu dalam kehidupan siswa.

Kelompok responden kedua yaitu siswa sudah belajar kalor dominan berada pada kategori material motion-cycle sebanyak lima siswa. Pada kategori material motion-cycle siswa menjelaskan bahwa konduksi kalor terjadi dengan perpindahan partikel penyusunnya dan membentuk siklus. Konsepsi ini sangat tidak sesuai dengan sifat benda padat yang rigid. Kategori material motion cycle lebih buruk jika dibandingkan material motion. Kesalahan yang sangat fatal ketika siswa sudah belajar suhu kalor dominan berada pada kategori material motioncycle. Namun, pada kelompok ini juga terdapat masing-masing dua orang yang masuk ke dalam kategori material motion, material motionsubstance, energy dan interaction. Kemudian masing-masing satu siswa yang masuk ke dalam substance-energy dan no respons. No respons yaitu siswa tidak memberikan respon atau jawaban ketika ditanyakan tentang pengetahuannya mengenai konduksi kalor. Penyebaran jumlah siswa pada kelompok ini cukup bervariasi. Terdapat dua orang siswa yang memiliki konsep ilmiah namun juga dominan diantaranya memiliki konsep yang sangat buruk yaitu material motion-cycle dimana siswa menjelaskan bahwa partikel penyusun pada logam ikut berpindah.

Hasil penelitian yang disajikan pada tabel 2 telah diuji reliabilitasnya oleh dua rater. Hasil yang diperoleh tidak terdapat perbedaan persetujuan antara keduanya.

\section{Analogi Proses Konduksi Kalor}

Analogi konduksi kalor diperoleh melalui wawancara mengenai suatu fenomena. Terdapat tujuh kategori analogi konduksi kalor pada penelitian ini yang disajikan dalam bentuk tabel 3. 
Tabel 2. Konsepsi konduksi kalor siswa

\begin{tabular}{|c|c|c|c|}
\hline \multirow[b]{2}{*}{ Kategori } & \multirow[b]{2}{*}{ Konsepsi Kalor } & \multicolumn{2}{|c|}{ Jumlah } \\
\hline & & $\begin{array}{l}\text { Siswa sudah } \\
\text { Belajar Kalor }\end{array}$ & $\begin{array}{l}\text { Siswa belum } \\
\text { Belajar Kalor }\end{array}$ \\
\hline Intreraction & $\begin{array}{l}\text { Konduksi kalor sebagai hasil dari partikel-partikel yang saling } \\
\text { bertumbukan/bergetar. Molekul bergerak lebih cepat di daerah } \\
\text { yang suhunya lebih tinggi, akibat getaran/tumbukan tersebut } \\
\text { kemudian akan mempengaruhi suhu. }\end{array}$ & 0 & 2 \\
\hline Energy & $\begin{array}{l}\text { Konduksi kalor sebagai hasil dari kalor yang mengalir dari suhu } \\
\text { tinggi ke suhu rendah. }\end{array}$ & 3 & 2 \\
\hline Subtance & $\begin{array}{l}\text { Konduksi kalor sebagai hasil dari partikel-partikel panas yang } \\
\text { bergerak dari satu benda ke benda lain. }\end{array}$ & 0 & 0 \\
\hline $\begin{array}{l}\text { Subtance- } \\
\text { Energy }\end{array}$ & Konsepsi kalor gabungan dari kategori Subtance dan Energy & 0 & 1 \\
\hline Medium & $\begin{array}{l}\text { Konduksi kalor sebagai zat perantara/penghantar untuk } \\
\text { merambatkan kalor }\end{array}$ & 0 & 0 \\
\hline $\begin{array}{c}\text { Sample based } \\
\text { convection }\end{array}$ & $\begin{array}{l}\text { Konduksi kalor dicontohkan ketika masak air, maka fenomena } \\
\text { konduksi yang terjadi adalah air mendidih }\end{array}$ & 0 & 0 \\
\hline $\begin{array}{l}\text { Medium- } \\
\text { Sample Based } \\
\text { Convection }\end{array}$ & $\begin{array}{l}\text { Konsepsi kalor gabungan dari kategori Medium dan Sample } \\
\text { Based Convection }\end{array}$ & 1 & 0 \\
\hline $\begin{array}{l}\text { Sample Based } \\
\text { Conduction }\end{array}$ & $\begin{array}{l}\text { Konduksi kalor dicontohkan dengan dua benda yang berbeda } \\
\text { suhu ditempelkan lalu benda yang awalnya dingin menjadi } \\
\text { panas setelah ditempelkan }\end{array}$ & 1 & 0 \\
\hline Radiation & Konduksi kalor sebagai proses radiasi matahari ke bumi. & 1 & 0 \\
\hline $\begin{array}{l}\text { Material } \\
\text { Motion }\end{array}$ & $\begin{array}{l}\text { Konduksi kalor merupakan perpindahan kalor melalui } \\
\text { perpindahan partikel penyusunnya. }\end{array}$ & 4 & 2 \\
\hline Cycle & $\begin{array}{l}\text { Konduksi kalor sebagai hasil dari partikel-partikel yang } \\
\text { berpindah sehingga membentuk siklus. }\end{array}$ & 0 & 0 \\
\hline $\begin{array}{c}\text { Material } \\
\text { Motion-Cycle }\end{array}$ & $\begin{array}{l}\text { Konsepsi kalor gabungan dari kategori Material Motion dan } \\
\text { Cycle }\end{array}$ & 3 & 5 \\
\hline $\begin{array}{l}\text { Material } \\
\text { Motion- } \\
\text { Subtance }\end{array}$ & $\begin{array}{l}\text { Konsepsi kalor gabungan dari kategori Material Motion dan } \\
\text { Subtance }\end{array}$ & 2 & 2 \\
\hline No Respons & & 0 & 1 \\
\hline Total & & 15 & 15 \\
\hline
\end{tabular}

Tabel 3. Analogi-proses konduksi kalor pada batang logam dan aluminium

\begin{tabular}{|c|c|c|c|c|}
\hline \multirow{3}{*}{ Kategori } & \multicolumn{4}{|c|}{ Jumlah } \\
\hline & \multicolumn{2}{|c|}{ Aluminium } & \multicolumn{2}{|c|}{ Kayu } \\
\hline & $\begin{array}{l}\text { Siswa belum } \\
\text { belajar kalor }\end{array}$ & $\begin{array}{l}\text { Siswa sudah } \\
\text { belajar kalor }\end{array}$ & $\begin{array}{l}\text { Siswa belum } \\
\text { belajar kalor }\end{array}$ & $\begin{array}{l}\text { Siswa sudah } \\
\text { belajar kalor }\end{array}$ \\
\hline Marching & 0 & 0 & 0 & 0 \\
\hline Floading & 0 & 0 & 0 & 0 \\
\hline Gradient & 7 & 6 & 8 & 9 \\
\hline Gradient-Floading & 8 & 9 & 2 & 0 \\
\hline Stacking & 0 & 0 & 0 & 0 \\
\hline Gradient-Stacking & 0 & 0 & 0 & 1 \\
\hline Floading non heat & 0 & 0 & 5 & 5 \\
\hline Total & 15 & 15 & 15 & 15 \\
\hline
\end{tabular}


Berdasarkan tabel 3 ditunjukkan bahwa terdapat tujuh analogi-proses konduksi kalor: marching, flooding, gradient, gradient-floading, Analogi pertama adalah marching dimana konduksi kalor sebagai hasil gerakan langkah demi langkah. Setelah mem asuki objek, kalor stacking, gradientstacking, floading non heat. Empat kategori pertama merupakan hasil penelitian dari Chiou \& Anderson (2010) dan kategori stacking dan gradient-stacking merupakan hasil penelitian dari I. M. Sari, Malik, Saepuzaman, Rusdiana, \& Ramalis (2019), sedangkan kategori terakhir merupakan kategori yang ditemukan pada penelitian ini.

Analogi Marching dimana konduksi kalor sebagai hasil gerakan langkah demi langkah. Setelah memasuki objek, melangkah kedepan dan teratur menjelang akhir lainnya. Sementara daerah yang terkena oleh gerakan kalor mencapai kesetimbangan termal segera dengan wilayah depan, daerah di luar gerakan kalor tetap termal tidak dipengaruhi.

Analogi mendasar kedua adalah analogi floading yaitu konduksi kalor sebagai proses meningkatnya aliran secara bertahap. Setelah memasuki objek, kalor dengan segera dan merata di seluruh objek. Suhu meningkat di seluruh objek pada tingkat yang konstan sampai kesetimbangan termal tercapai.

Analogi ketiga adalah gradient yaitu hasil konduksi kalor secara gradien. Setelah memasuki objek, kalor bergegas kedepan, dan jumlah kalor yang di transmisikan secara bertahap menurun sepanjang objek. Suhu di daerah yang berbeda dari peningkatan objek berbanding terbalik dengan jarak antara wilayah dan sumber kalor. Pada batang kayu, siswa yang sudah belajar dan siswa yang belum belajar dominan masuk ke dalam kategori gradient, yaitu sebanyak delapan orang siswa belum belajar kalor dan sembilan orang siswa sudah belajar kalor. Kategori ini adalah kategori yang diterima secara ilmiah saat sistem tidak terisolasi.
Analogi keempat merupakan analogi ganda yaitu gradient-floading yaitu kombinsi dari analogi gradient dan analogi floading. Pada kondisi ini analogi gradient berada pada fase sementara kemudian berlanjut analogi floading. Pada batang aluminium, seluruh kelompok sampel dominan masuk ke dalam kategori gradient-floading. Pada batang aluminium analogi ini dominan dimiliki dua kelompok responden tersebut. Siswa belum belajar kalor sebanyak delapan orang dan siswa sudah belajar kalor sebanyak sembilan orang. Analogi ini juga dimiliki dua orang siswa belum belajar kalor di mana kategori ini terjadi pada batang kayu.

Kemudian analogi kelima adalah stacking, di mana hasil konduksi kalor berlangsung secara langkah demi langkah. Setelah memasuki objek, kalor bergegas kedepan dan menumpuk di setiap titik. Pada fase pertama pemanasan, kalor menumpuk di titik pusat batang. Pada fase kedua pemanasan, semua partikel panas menumpuk di ujung batang. Temperatur tertinggi berada di ujung batang. Analogi keenam adalah gradientstacking. Pada kondisi ini analogi gradient berada pada fase sementara kemudian berlanjut ke analogi stacking. Terdapat satu siswa yang masuk kedalam kategori gradient-stacking di mana kategori ini terjadi pada batang kayu. Sementara untuk kategori ketujuh merupakan kategori yang baru ditemukan khususnya pada kayu.

Analogi floading non heat di mana tidak ada perambatan kalor di kayu perambatan dapat terjadi pada titik yang terdekat dengan sumber kalor. Analogi ini dimiliki masing-masing lima siswa dari dua kelompok responden. Berdasarkan beberapa analogi yang ditemukan, pada batang aluminium jawaban responden tidak jauh berbeda, hanya terbagi kedalam dua kelompok kategori. Sedangkan pada batang kayu jawaban responden sangat bervariasi, kategori yang baru ditemukan menunjukkan ketidakfahaman responden terhadap sifat bahan (konduktor/isolator). 
Hasil penelitian yang disajikan pada tabel 3 telah diuji reliabilitasnya oleh dua rater. Reliabilitas pada analogi konduksi kalor batang aluminium tidak terdapat perbedaan persetujuan antara kedua rater. Sedangan pada analogi konduksi kalor batang kayu diperoleh nilai kappa sebesar 0,66 dan masuk kedalam kategori baik.

\section{Model Mental Siswa}

Model Mental siswa dinyatakan dalam hubungan konsepsi dan analogi proses konduksi yang di jawab siswa. Kombinasi ini dapat mewakili model mental dari segi mekanisme yang mendasar konduksi kalor (Chiou dan Anderson 2010). Model Mental siswa ditunjukkan pada tabel 4. Pada tabel 4 ditunjukkan sebaran model mental siswa belum belajar kalor. Model mental didasari oleh kekonsistenan jawaban siswa (Bonello 2008).

Lima dari limabelas siswa masih belum memahami dengan baik materi konduksi kalor, hal ini ditunjukkan terdapat lima siswa yang menjawab analogi proses konduksi kalor pada kayu adalah floading non heat. Siswa nomor lima dan delapan memiliki model mental konduksi kalor yang sama, dimana konsepsi kalor masuk ke dalam kategori energy dan analogi konduksi kalornya adalah gradient-floading pada aluminium dan gradient pada kayu. Kemudian ditemukan juga siswa nomor sembilan dan sepuluh memiliki model mental konduksi kalor yang sama, yaitu material subtance untuk konsepsi kalor dan pada analogi konduksi kalor menjawab gradient (batang aluminium) dan floading non heat (batang kayu). Sedangkan siswa lainnya memiliki model mental konduksi kalor yang berbeda-beda yang sangat bervariasi. Pada kelompok ini tidak ditemukan siswa yang memiliki model mental ilmiah.

Kemudian model mental siswa sudah belajar kalor disajikan pada tabel 5. Pada tabel 5 di tunjukkan data model mental konduksi kalor siswa sudah belajar kalor. Hubungan konsepsi konduksi kalor dan analogi proses dapat menjadi model mental seseorang (Chiou dan Anderson 2010). Tidak jauh berbeda dengan siswa belum belajar kalor, kelompok responden ini juga menunjukkan model mental konduksi kalor yang sangat unik. Terdapat tiga belas siswa yang belum memahami konduksi kalor secara utuh. Hal ini di tunjukkan bahwa siswa menjawab floading non heat untuk proses konduksi kalor pada batang kayu.

Tabel 4. Model mental siswa belum belajar kalor

\begin{tabular}{|c|c|c|c|c|c|c|}
\hline \multirow{3}{*}{ Siswa } & \multirow{3}{*}{ Konsepsi konduksi kalor } & \multicolumn{5}{|c|}{ Analogi-Pross Konduksi } \\
\hline & & \multicolumn{2}{|c|}{ Gradient } & \multicolumn{2}{|c|}{ Gradient-Floading } & \multirow{2}{*}{$\frac{\text { Floading non heat }}{\text { Kayu }}$} \\
\hline & & Aluminium & Kayu & Aluminium & Kayu & \\
\hline 1 & Material Motion-Cycle & 1 & 1 & & & \\
\hline 2 & Material Motion & 1 & & & & 1 \\
\hline 3 & Material Motion & & & 1 & & 1 \\
\hline 4 & Radiation & 1 & & & & 1 \\
\hline 5 & Energy & & 1 & 1 & & \\
\hline 6 & Medium-Sample based convection & 1 & & & 1 & \\
\hline 7 & Material Motion-Cycle & & 1 & 1 & & \\
\hline 8 & Energy & & 1 & 1 & & \\
\hline 9 & Material Motion-subtance & 1 & & & & 1 \\
\hline 10 & Material Motion-subtance & 1 & & & & 1 \\
\hline 11 & Energy & & & 1 & 1 & \\
\hline 12 & Material Motion & 1 & & 1 & & \\
\hline 13 & sample based conduction & & 1 & 1 & & \\
\hline 14 & Material Motion & & 1 & 1 & & \\
\hline 15 & Material Motion-cycle & & & 1 & 1 & \\
\hline
\end{tabular}


JoTaLP: Journal of Teaching and Learning Physics 6, 1 (2021): 39-48

Website: http://journal.uinsgd.ac.id/index.php/jtlp/index ISSN 2580-3107 (online) ISSN 2528-5505 (print)

Tabel 5. Model mental siswa sudah belajar kalor

\begin{tabular}{|c|c|c|c|c|c|c|c|}
\hline \multirow{3}{*}{ Siswa } & \multirow{3}{*}{$\begin{array}{l}\text { Konsepsi Konduksi } \\
\text { Kalor }\end{array}$} & \multicolumn{6}{|c|}{ Analogi-Proses Konduksi Kalor } \\
\hline & & \multicolumn{2}{|c|}{ Gradient } & \multicolumn{2}{|c|}{ Gradient-Floading } & \multirow{2}{*}{$\begin{array}{c}\begin{array}{c}\text { Floading } \\
\text { non heat }\end{array} \\
\text { Kayu }\end{array}$} & \multirow{2}{*}{$\begin{array}{c}\text { Gradient } \\
\text { Stacking } \\
\text { Kayu }\end{array}$} \\
\hline & & Aluminium & Kayu & Aluminium & Kayu & & \\
\hline 1 & $\begin{array}{l}\text { Material Motion- } \\
\text { Subtance }\end{array}$ & 1 & 1 & & & & \\
\hline 2 & No Respons & 1 & & & & 1 & \\
\hline 3 & Interaction & 1 & 1 & & & & \\
\hline 4 & Material Motion-Cycle & & & 1 & & 1 & \\
\hline 5 & Subtance-Energy & & & 1 & & 1 & \\
\hline 6 & Material Motion-Cycle & 1 & 1 & & & & \\
\hline 7 & Material Motion-Cycle & & 1 & 1 & & & \\
\hline 8 & Energy & 1 & 1 & & & & \\
\hline 9 & Material Motion & & & 1 & & & 1 \\
\hline 10 & Energy & & 1 & 1 & & & \\
\hline 11 & Material Motion & & 1 & 1 & & & \\
\hline 12 & Interaction & & 1 & 1 & & & \\
\hline 13 & Material Motion-Cycle & & & 1 & & 1 & \\
\hline 14 & $\begin{array}{l}\text { Material Motion- } \\
\text { Subtance }\end{array}$ & 1 & & & & 1 & \\
\hline 15 & Material Motion-cycle & & & 1 & & 1 & \\
\hline
\end{tabular}

Enam siswa yang menjawab floading non heat pada analogi kayu juga memiliki konsepsi konduksi kalor yang tidak tepat diantaranya material motion-cycle, material motion-subtance, subtance-energy dan no respons. Siswa yang masuk ke dalam kategori no respons merupakan siswa yang tidak memiliki konsepsi konduksi kalor, sehingga satu orang siswa tersebut tidak memiliki model mental konduksi kalor. Enam siswa lainnya memiliki model mental yang beragam dan berbeda dari penelitian sebelumnya, seperti ditunjukkan pada tabel 5 . Kemudian pada kelompok siswa yang sudah belajar kalor terdapat dua orang siswa yang memiliki konsep konduksi kalor yang ilmiah. Meskipun kedua siswa tersebut memiliki analogi konduksi kalor pada kayu dan logam berbeda, namun perbedaan ini tidak terlalu berarti. Sehingga pada kelompok ini ditemukan dua siswa yang memiliki model mental ilmiah.

\section{KESIMPULAN}

Berdarkan penelitian yang dilakukan ditemukan bahwa profil model mental konduksi kalor pada penelitian ini sangat unik, bervariasi dan berbeda dari penelitian sebelumnya. Hal ini menguatkan fakta bahwa model mental merupakan sesuatu yang dinamis. Pada kelompok siswa yang belum belajar kalor tidak ditemukan siswa yang memiliki model mental ilmiah. Kemudian untuk kelompok siswa yang sudah belajar kalor ditemukan dua siswa memiliki model mental yang ilmiah, 12 siswa memiliki model mental tidak ilmiah dan satu siswa tidak memiliki model mental konduksi kalor karena tidak mampu menjelaskan konsep kalor. Model mental ilmiah terbentuk setelah pembelajaran, oleh karena itu diperlukan pengembangan model pembelajaran yang dapat memfasilitasi pembentukan model mental ilmiah.

\section{DAFTAR PUSTAKA}

Amalia, R., IM Sari, \& P. Sinaga. (2016). International Conference on Recent Trends in Physics (ICRTP 2012). Journal of Physics: Conference Series vol. 365, p. 011001.

Bohori, M., \& Liliawati, W. (2019). Analisis penguasaan konsep siswa menggunakan 
Rasch Model pada materi usaha dan energi. Prosiding Seminar Nasional Fisika pp. 138143.

Bonello, M. (2008) Six Grade Mental Models' of Physical Education Concepts: A Framework Theory Perspectivez. University of Maryland.

Chiou, Guo Li \& O. Roger Anderson. (2010) A study of undergraduate physics students' understanding of heat conduction based on mental model theory and an ontologyprocess analysis. Science Education 94(5):825-54. http://doi.org/ $10.1002 /$ sce. 20385

Fauzi, Dessy (2017) Identifikasi Model Mental Siswa SMK pada Materi Konduksi Kalor. Doctoral dissertation, Universitas Pendidikan Indonesia

Hamzah, K., Liliawati, W., \& Samsudin, A. (2019, November). Identification of misconceptions on global warming material: impact and solutions at middle school. Journal of Physics: Conference Series vol. 1280, No. 5, p. 052065. http://doi.org/10.1088/17426596/1280/5/052065

Jansoon, N., Coll, R. K., \& Somsook, E. (2009). Understanding Mental Models of Dilution in Thai Students. International Journal of Environmental and Science Education, 4(2), 147-168.

Lin, J. W., \& Chiu, M. H. (2007). Exploring the characteristics and diverse sources of students' mental models of acids and bases. International Journal of Science Education, 29(6), 771-803 http://doi.org/ 10.1080/09500690600855559

Mayub, A. 2005. E-Learning Fisika Berbasiskan Macromedia Flash MX. Yogyakarta: Graha Ilmu.

Norman, D. A. (1983). Some observations on mental models. Mental models, 7(112), 714.

Rahayu, S., \& Purwanto, J. (2013). Identifikasi Model Mental Siswa SMA Kelas X pada Materi Hukum Newton tentang Gerak. Kaunia: Integration and Interconnection
Islam and Science, 9 (2), 12-20.

Sari, I. M., Malik, A., Saepuzaman, D., Rusdiana, D., \& Ramalis, T. R. (2019). Pre-service physics teachers' mental models of heat conduction: a case study of the processanalogy of heat conduction. Journal of Physics: Conference Series vol. 1157, no. 3, p. 032073. http://doi.org/10.1088/17426596/1157/3/032073

Sari, I. M., Ahmad, S. F., \& Amsor, A. (2019). Peningkatan Keterampilan Generik Sains pada Materi Tata Surya melalui Pembelajaran Berbantuan Aplikasi Solar System Scope untuk Siswa SMP. Journal of Teaching and Learning Physics, 4(2), 1-17. https://doi.org/10.15575/jotalp.v4i2.429 4

Sari, I. M., \& Saepuzzaman, D. (2015). Physics Students' Mental Model and Prediction in Heat Convection Concept. 2015 International Conference on Innovation in Engineering and Vocational Education. pp. 224-227.

Sari, I. M., Fauzi, D., Malik, A., Saepuzaman, D., Ramalis, T. R., \& Rusdiana, D. (2019). Excavating the Quality of Vocational Students' Mental Models and Prediction on Heat Conduction. Journal of Physics: Conference Series vol. 1204, p. 012042 http://doi.org/10.1088/17426596/1204/1/012042

Senge, P. M. (2004) The Fifth Discipline:The art and practice of learning organisation.

Shalihah, A., Mulhayatiah, D., \& Alatas, F. (2016). Identifikasi Miskonsepsi Menggunakan Tes Diagnostik Three-tier Pada Hukum Newton Dan Penerapannya. Journal of Teaching and Learning Physics, 1(1), 24-33. https://doi.org/10.15575/jotalp.v1i1.343 8

Supriyatman, S., Suhandi, A., Rusdiana, D., Samsudin, A., Wibowo, F. C., \& Mansyur, J. (2018). Design of Experimental Problem Solving-Based Learning Program to Improve Mental Model and to Enhance Mental-Modeling Ability. Jurnal Pendidikan Fisika Indonesia, 14(2), 73-82. 
JoTaLP: Journal of Teaching and Learning Physics 6, 1 (2021): 39-48

Website: http://journal.uinsgd.ac.id/index.php/jtlp/index ISSN 2580-3107 (online) ISSN 2528-5505 (print)

https://doi.org/10.15294/jpfi.v14i2.6279

Wenning, C. J. (2008). Dealing more effectively with alternative conceptions in science. Journal of Physics Teacher Education Online,
5(1), 11-19.

Widhiarso, Wahyu. 2005. Mengestimasi Reliabilitas. Yogyakarta. 